\title{
Infrared Thermography for Characterising Density Variation of Shield Concretes
}

\section{M.Menaka1, D.Sharath ${ }^{1}$, Ajay Rawat ${ }^{2}$, B.Venkatraman², Ashok Kumar ${ }^{3}$, R.Preetha ${ }^{3}$ and Sivathanu Pillai $^{3}$}

1. Quality Assurance Division, Indira Gandhi Centre for Atomic Research, Kalpakkam-603102

2. Radiological Safety Division, Indira Gandhi Centre for Atomic Research, Kalpakkam-603102

3. Civil Engineering Group, Indira Gandhi Centre for Atomic Research, Kalpakkam-603102

Email: menaka@igcar.gov.in

High density concrete (HDC) is widely used for radiation shielding purposes in nuclear reactors as part of vault and top shields where the temperature is expected to vary from $65^{\circ} \mathrm{C}$ to $120^{\circ} \mathrm{C}$. Radiation shielding characteristics of concrete mainly depend on its density, amount and type of aggregates added in the mixture and the moisture content. For this study both step heating and lock-in techniques has been adopted for investigating the concrete samples. The thermographic results clearly indicated the variation in aggregates and their distribution in the sample. The variation in the aggregrates in sample is directly influence by the density of the concrete sample. There was clear distinguished change in the phase value and thermal decay curve between normal concrete sample, hematite aggregate sample and concrete sample with steel balls of $2-4 \mathrm{~mm}$ diameter. In the present study, the effect of high temperature $\left(120^{\circ} \mathrm{C}\right)$ for varying durations (14 and 28 days) on the properties of high density concrete made of granite and having haematite and steel shots as aggregate was also investigated. The parameters like density, variation due to heat treatment were compared with that of ordinary density concrete. The density variation is observed only during first 14 days of heat treatment. Beyond 14 days there is no significant change in the density values. It is also observed that ordinary concrete showed more density reduction compared to high density concrete.

Keywords: High Density Concrete, lock-in thermography, density 